\title{
Impact of an improved shortwave radiation scheme in the MAECHAM5 General Circulation Model
}

\author{
C. Cagnazzo $^{1, *}$, E. Manzini ${ }^{1, *}$, M. A. Giorgetta ${ }^{2}$, P. M. De F. Forster ${ }^{3}$, and J. J. Morcrette $^{4}$ \\ ${ }^{1}$ Istituto Nazionale di Geofisica e Vulcanologia, Bologna, Italy \\ ${ }^{2}$ Max Planck Institute for Meteorology, Hamburg, Germany \\ ${ }^{3}$ School of Earth and Environment, University of Leeds, UK \\ ${ }^{4}$ European Center for Medium-Range Weather Forecasts, UK \\ *also at: Centro Euro-Mediterraneo per i Cambiamenti Climatici, Bologna, Italy
}

Received: 4 October 2006 - Published in Atmos. Chem. Phys. Discuss.: 7 November 2006

Revised: 5 March 2007 - Accepted: 2 May 2007 - Published: 14 May 2007

\begin{abstract}
In order to improve the representation of ozone absorption in the stratosphere of the MAECHAM5 general circulation model, the spectral resolution of the shortwave radiation parameterization used in the model has been increased from 4 to 6 bands. Two 20-years simulations with the general circulation model have been performed, one with the standard and the other with the newly introduced parameterization respectively, to evaluate the temperature and dynamical changes arising from the two different representations of the shortwave radiative transfer. In the simulation with the increased spectral resolution in the radiation parameterization, a significant warming of almost the entire model domain is reported. At the summer stratopause the temperature increase is about $6 \mathrm{~K}$ and alleviates the cold bias present in the model when the standard radiation scheme is used. These general circulation model results are consistent both with previous validation of the radiation scheme and with the offline clear-sky comparison performed in the current work with a discrete ordinate 4 stream scattering line by line radiative transfer model. The offline validation shows a substantial reduction of the daily averaged shortwave heating rate bias (1-2 K/day cooling) that occurs for the standard radiation parameterization in the upper stratosphere, present under a range of atmospheric conditions. Therefore, the 6 band shortwave radiation parameterization is considered to be better suited for the representation of the ozone absorption in the stratosphere than the 4 band parameterization. Concerning the dynamical response in the general circulation model, it is found that the reported warming at the summer stratopause induces stronger zonal mean zonal winds in the middle atmosphere. These stronger zonal mean zonal winds thereafter appear to produce a dynamical feedback that results in
\end{abstract}

Correspondence to: C. Cagnazzo

(cagnazzo@bo.ingv.it) a dynamical warming (cooling) of the polar winter (summer) mesosphere, caused by an increased downward (upward) circulation in the winter (summer) hemisphere. In addition, the comparison of the two simulations performed with the general circulation model shows that the increase in the spectral resolution of the shortwave radiation and the associated changes in the cloud optical properties result in a warming $(0.5-1 \mathrm{~K})$ and moistening $(3 \%-12 \%)$ of the upper tropical troposphere. By comparing these modeled differences with previous works, it appears that the reported changes in the solar radiation scheme contribute to improve the model mean temperature also in the troposphere.

\section{Introduction}

Solar radiation is the fundamental energy source for atmospheric motions. A proper representation of radiative transfer in atmosphere General Circulation Models (GCMs) has therefore always been a necessary condition for a correct simulation of the modelled energy content of the planet. Radiative transfer parameterizations for GCMs have indeed been among the first parameterizations to be developed to a high degree of complexity and to be the subject of systematic and intensive validations. See for instance the recent work by Halthore et al. (2005) and references therein. Many issues related to radiative transfer that are now under investigation, generally focus on the treatment of clouds and aerosols.

Another aspect, that may have not received so much attention, is the representation of radiative transfer in the stratosphere. Within the GRIPS (GCM Intercomparison for SPARC, Stratospheric Processes and their Role in Climate) project, the first intercomparison of middle atmosphere GCMs showed a general cold bias in the global averaged

Published by Copernicus Publications on behalf of the European Geosciences Union. 
Table 1. SW4 and SW6 bands and absorbing gases.

\begin{tabular}{llll}
\hline ECHAM5-SW4 bands & Gases & ECHAM5-SW6 bands & Gases \\
\hline \multirow{2}{*}{$250-690 \mathrm{~nm}$} & & $185-250 \mathrm{~nm}$ & $\mathrm{O} 3$ \\
& $\mathrm{H}_{2} \mathrm{O}, \mathrm{O}_{3}, \mathrm{UMG}$ & $250-440 \mathrm{~nm}$ & $\mathrm{O}_{3}, \mathrm{UMG}$ \\
$690-1190 \mathrm{~nm}$ & & $440-690 \mathrm{~nm}$ & $\mathrm{H}_{2} \mathrm{O}, \mathrm{O}_{3}, \mathrm{UMG}$ \\
$1190-2380 \mathrm{~nm}$ & $\mathrm{H}_{2} \mathrm{O}, \mathrm{UMG}$ & $690-1190 \mathrm{~nm}$ & $\mathrm{H}_{2} \mathrm{O}, \mathrm{UMG}$ \\
$2380-4000 \mathrm{~nm}$ & $\mathrm{H}_{2} \mathrm{O}, \mathrm{UMG}$ & $1190-2380 \mathrm{~nm}$ & $\mathrm{H}_{2} \mathrm{O}, \mathrm{UMG}$ \\
& $\mathrm{H}_{2} \mathrm{O}, \mathrm{O}_{3}, \mathrm{UMG}$ & $2380-4000 \mathrm{~nm}$ & $\mathrm{H}_{2} \mathrm{O}, \mathrm{O}_{3}, \mathrm{UMG}$ \\
\hline
\end{tabular}

Table 2. Concentrations of Greenhouse gases used in the offline calculations.

\begin{tabular}{ll}
\hline GHG gases & Concentration \\
\hline $\mathrm{CO}_{2}$ & $287 \mathrm{ppmv}$ \\
$\mathrm{CH}_{4}$ & $806 \mathrm{ppbv}$ \\
$\mathrm{N}_{2} \mathrm{O}$ & $275 \mathrm{ppbv}$ \\
\hline
\end{tabular}

temperature (Pawson et al., 2000), indicative of systematic uncertainties in the radiative transfer parameterizations used in the models. More recently, the evaluation of radiative parameterizations employed in GCMs that include the stratosphere is part of the Chemistry Climate Model Validation (CCMVAL, Eyring et al., 2005) project.

The main purposes of this work are to improve the representation of the ozone absorption in the stratosphere of the MAECHAM5 middle atmosphere GCM (Manzini et al., 2006), and to evaluate its impact on the simulated mean temperature. Therefore, the standard shortwave radiation parameterization of the MAECHAM5 model has been substituted with the one in use in the ECMWF (European Centre for Medium-Range Weather Forecasts) model since April 2002. The upgrade in the shortwave parameterization, carried out at the ECMWF and the University of Lille, consists in the increase of the spectral resolution from 1 to 3 bands in the UV-Visible part of the solar spectrum. In the application of this upgraded parameterization to the MAECHAM5 model, the radiative transfer within the new bands is calculated for the entire model domain (as done for the remaining part of the solar spectrum), namely between the top of the model and the Earth's surface, thus allowing a consistent treatment of absorption and scattering in the whole model atmosphere. Consequently, this approach needs to include a modification of the treatment of the cloud optical properties. We follow this approach for its comprehensiveness.

A previous work (Manzini and McFarlane, 1998) based on an earlier version of the MAECHAM5 model found an average cold bias ( $5 \mathrm{~K}$ to $15 \mathrm{~K}$ ) in the summer upper stratosphere, insensitive to the parameterization of atmospheric gravity waves. Subsequently, an average cold bias ( $4 \mathrm{~K}$ to $8 \mathrm{~K}$ ) between $30^{\circ} \mathrm{S}$ and $30^{\circ} \mathrm{N}$ in the upper stratosphere with respect to 9 years of HALOE (Halogen Occultation Experiment) temperature is reported by Steil et al. (2003), in an application of the MAECHAM4 model coupled to a chemistry model. A similar cold bias with respect to an average of re-analysis data has also been reported by Egorova et al. (2005) for the coupling of MAECHAM4 to a different chemistry model. Given the coarse spectral resolution of the solar radiation scheme in the UV-visible spectrum (unchanged in all the reported applications of MAECHAM4), a plausible reason for this cold bias is an underestimation of ozone absorption in the stratosphere of the model. Although many aspects of the MAECHAM5 model are new or modified with respect to its predecessor MAECHAM4, the treatment of the UV-visible bands has not changed. Therefore, it is of interest to investigate the effect of changes to the UV-visible band treatment in the MAECHAM5 model.

In Sect. 2 the GCM, the standard and upgraded solar radiation parameterizations and the methodology are introduced. Section 3 is an offline comparison of the two parameterizations with a discrete-ordinate 4 stream scattering line by line model. The radiative and dynamical responses of the GCM to the changes in the solar radiation parameterization are presented in Sect. 4, focusing on the middle atmosphere and the troposphere separately. Conclusion are drawn in Sect. 5.

\section{Model and methodology}

The MAECHAM5 model used in this work is the latest version (Manzini et al., 2006) of the middle atmosphere GCM based on the ECHAM model suite (Roeckner et al., 2006). Concerning gravity wave parameterizations, the MAECHAM5 model includes an orographic gravity wave drag parameterization (Lott and Miller, 1997) and the Hines parameterization of the momentum flux deposition from an atmospheric gravity wave spectrum (Hines, 1997). The source spectrum of the Hines parameterizations is as specified in Manzini et al. (2006). 
Table 3. Solar zenith angles (SZAs), Gaussian weights and relative day lenght used in the offline calculations, for the mid-latitude summer (MLS), mid-laltitude winter (MLW) and tropical (TRP) climatological conditions.

\begin{tabular}{lllll}
\hline & MLS & MLW & TRP & GAUSSIAN WEIGHT \\
\hline SZA1 & 84.468 & 86.1329 & 82.1345 & 0.23693 \\
SZA2 & 56.7374 & 76.6687 & 51.8298 & 0.47863 \\
SZA3 & 27.3919 & 69.9054 & 12.7973 & 0.28444 \\
DAYLENGHT & 0.653446 & 0.34655 & 0.500000 & \\
\hline
\end{tabular}

\subsection{Radiation parameterizations}

Aspects of the radiation parameterization and its validation are described in Roeckner et al. (2003) and Wild and Roeckner (2006), respectively. The standard spectral resolution of the solar radiation parameterization is 4 bands (referenced here as SW4, see Table 1), with 1 band for the UV and visible $(250$ to $690 \mathrm{~nm})$ and three bands for the near-infrared (690 to $4000 \mathrm{~nm}$ ). The parameterization follows the approach of Fouquart and Bonnel (1980). It includes absorption by water vapor and ozone, both varying in time and space, and $\mathrm{CO}_{2}$, $\mathrm{N}_{2} \mathrm{O}, \mathrm{CO}, \mathrm{CH}_{4}$ and $\mathrm{O}_{2}$ as Uniformly Mixed Gases (UMG), and Rayleigh, aerosol and cloud particle scattering. Absorbing gases are also indicated in Table 1.

The parameterization has been upgraded by increasing its spectral resolution from 4 to 6 bands. The 6-band version of the radiation parameterization (hereinafter SW6) in use at ECMWF has been implemented and adapted to the MAECHAM5 model (see Table 1). The upgrade subdivided the 250-690 nm interval and added an extra band in the ultraviolet from 185 to $250 \mathrm{~nm}$, creating a total of three bands in the UV-visible spectral range $(185-250 \mathrm{~nm}, 250-440 \mathrm{~nm}$ and $440-690 \mathrm{~nm}$ ) and three bands for the Near-Infrared (690$1190 \mathrm{~nm}, 1190-2380 \mathrm{~nm}$ and $2380-4000 \mathrm{~nm}$ ). The extension to 6 bands has been performed in a consistent manner, so that the SW6 parameterization is used throughout the model atmosphere (between the top of the model and the surface). Therefore, the optical properties for water and ice clouds had to be changed. In the current implementation of the SW6 parameterization, the Fouquart et al. (1987) and Ebert and Curry (1992) derivations for the optical properties have been used, respectively for the water and ice clouds, following Morcrette et al. (2001) and Dubuisson et al. (1996).

\subsection{Design of the simulations}

Two 20-year simulations have been performed with the MAECHAM5 model: The first simulation (hereafter CTRL) with the SW4 parameterization and the second simulation (hereafter EXP) with the SW6 parameterization. Both simulations use triangular horizontal truncation at wavenumber 42 (T42) and 39 vertical levels from the surface to $80 \mathrm{~km}$ $(0.01 \mathrm{hPa})$. This model configuration is the one also used in
Manzini et al. (2006). The simulations are performed with climatological sea surface temperatures, specified ozone climatology and greenhouse gases for the 1990s (see Manzini et al., 2006, for details).

\section{Offline validation of SW6}

The SW6 parameterization has been originally developed at ECMWF and the University of Lille and tested against the Line-By-Line (LBL) model of Dubuisson et al. (1996). Thereafter, the behavior of the SW6 parameterization has been reported and compared to the previous SW4 parameterization in Iacono et al. (2002) where validation against the rapid radiative transfer radiation model in both clear-sky and cloudy-sky conditions is also discussed. Iacono et al. (2002) have shown that the SW6 parameterization significantly improves the representation of the clear sky and all-sky fluxes and heating rates relative to RRTM over the previous SW4 parameterization.

Here, the differences between the offline behavior of the SW4 and the SW6 parameterizations are further documented, with the focus on their behavior in the stratosphere. For the current offline validation, we use the Discrete-Ordinate 4 stream scattering model (Stamnes et al., 1998) coupled to the line by line Reference Forward Model (RFM, Dudhia, 1997). This sophisticated radiative transfer model has previously been used at the University of Reading as a reference calculation for GCM radiation schemes and found to be in excellent agreement with other line by line models (see Collins et al., 2006); this model is referred to here as LBL.

The offline comparison is carried out for climatological profiles of temperature, ozone, and water vapor for three specific cases: mid-latitude summer, mid-latitude winter and tropics. In each case, a clear-sky and aerosol-free atmosphere is assumed and greenhouse gases concentrations are as given in Table 2. For each case, a set of three solar zenith angles (SZAs) has been considered for the approximate computation of daily averages by Gaussian quadrature. Table 3 shows the solar zenith angles, Gaussian weights and the relative day length, by which the 3-point integral is multiplied to obtain daily averaged quantities. Daily averaged clear-sky shortwave fluxes and heating rates, using the SZA weights 
Table 4. Downward and Net fluxes $\left(\mathrm{W} \mathrm{m}^{-2}\right.$ ) at the Top of the Model and at the surface for the mid-latitude summer (MLS), mid-latitude winter (MLW) and tropical (TRP) climatological conditions and for each solar zenith angle considered. LBL values and SW6-LBL and SW4-LBL differences are shown

\begin{tabular}{lllll}
\hline MLS & TOM Down & TOM Net & Surf Down & Surf Net \\
\hline LBL sza1 & 130.8 & 102.6 & 68.3 & 62.1 \\
LBL sza2 & 744.3 & 652.5 & 569.0 & 517.4 \\
LBL sza3 & 1204.8 & 1077.1 & 976.4 & 887.9 \\
\hline SW6-LBL sza1 & 0. & -3.1 & -4.6 & -4.5 \\
SW6-LBL sza2 & 0. & -2.2 & -3.0 & -3.0 \\
SW6-LBL sza3 & 0. & -0.5 & -0.9 & -1.1 \\
\hline SW4-LBL sza1 & 0. & 1.7 & 4.3 & 3.5 \\
SW4-LBL sza2 & 0. & -0.17 & 11.0 & 9.4 \\
SW4-LBL sza3 & 0. & -0.2 & 15.3 & 13.7 \\
\hline MLW & TOM Down & TOM Net & Surf Down & Surf Net \\
\hline LBL sza1 & 91.5 & 69.9 & 44.0 & 39.6 \\
LBL sza2 & 312.9 & 258.6 & 211.2 & 190.0 \\
LBL sza3 & 466.2 & 395.0 & 339.8 & 305.8 \\
\hline SW6-LBL sza1 & 0. & -2.7 & -2.8 & -2.8 \\
SW6-LBL sza2 & 0. & -4.0 & -3.4 & -3.7 \\
SW6-LBL sza3 & 0. & -3.5 & -2.5 & -3.0 \\
\hline SW4-LBL sza1 & 0. & 1.4 & 3.7 & 3.0 \\
SW4-LBL sza2 & 0. & 1.0 & 7.3 & 6.0 \\
SW4-LBL sza3 & 0. & 0.7 & 9.0 & 7.5 \\
\hline TRP & TOM Down & TOM Net & Surf Down & Surf Net \\
\hline LBL sza1 & 185.7 & 150.4 & 98.1 & 89.9 \\
LBL sza2 & 838.6 & 746.3 & 612.4 & 561.6 \\
LBL sza3 & 1323.3 & 1198.9 & 1024.8 & 939.8 \\
\hline SW6-LBL sza1 & 0. & -2.7 & -6.2 & -6.1 \\
SW6-LBL sza2 & 0. & -1.1 & -1.9 & -2.3 \\
SW6-LBL sza3 & 0. & 0.6 & 1.4 & 1.3 \\
\hline SW4-LBL sza1 & 0. & 2.1 & 6.2 & 5.2 \\
SW4-LBL sza2 & 0. & -0.5 & 18.0 & 15.9 \\
SW4-LBL sza3 & 0. & -0.8 & 25.1 & 22.9 \\
\hline & & & & \\
\hline
\end{tabular}

are calculated by the LBL model and the SW6 and the SW4 schemes. Fluxes are shown in Table 4 for the top of the model (TOM) and the surface.

The LBL fluxes are integrated over the $185-4000 \mathrm{~nm}$ spectral range of the SW6 parameterization. The TOM downward fluxes are prescribed to be the same by construction $\left(1357 \mathrm{Wm}^{-2}\right)$ over the wavelength range employed by the radiation schemes (i.e. $185-4000 \mathrm{~nm}$ for the LBL and SW6 and 250-4000 $\mathrm{nm}$ for SW4).

Table 4 shows that at the TOM, the SW6 and SW4 net fluxes are in agreement with the LBL ones: SW6-LBL and SW4-LBL differences are within $3.5 \mathrm{~W} \mathrm{~m}^{-2}$. At the surface, the SW4 downward flux is overestimated, with particular large biases for small zenith angles for the tropics and mid- latitudes (from about $11 \mathrm{~W} \mathrm{~m}^{-2}$ to $25 \mathrm{~W} \mathrm{~m}^{-2}$ ). These biases are substantially reduced in the SW6 (SW6-LBL difference of a few $\mathrm{W} \mathrm{m}^{-2}$ ), indicating an improvement (increased atmospheric absorption) of the amount of radiation arriving at the surface.

Figure 1 shows the vertical profiles of the daily averaged clear-sky shortwave heating rate calculated by LBL, SW6 and SW4 for the three climatological conditions, as well as the SW6-LBL and SW4-LBL differences. Vertical profiles of shortwave heating rates for each solar zenith angle are also shown in the right panels of Fig. 1.

In the upper stratosphere, the region of interest in this work, the results shown in Fig. 1 indicate that the SW4 radiation scheme underestimates the daily averaged heating rate 

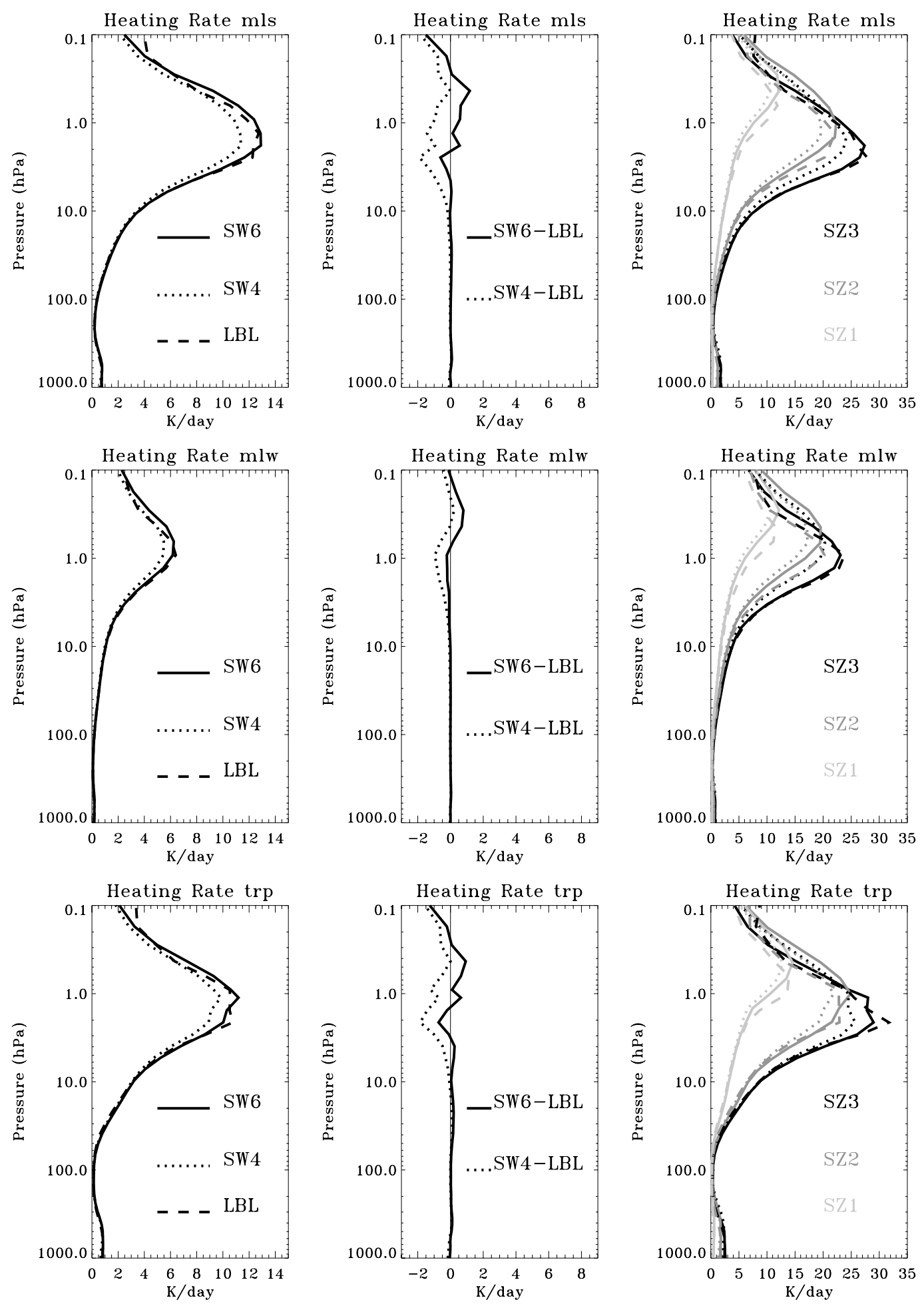

Fig. 1. Left: Daily averaged clear-sky shortwave heating rates (K/day) for SW6 (continuous curve), SW4 (dotted curve) and LBL (dashed curve). Middle: Difference of the daily averaged clear-sky shortwave heating rates (K/day) for SW6-LBL (continuous curve) and SW4LBL (dotted curve). Right: Clear-sky shortwave heating rates (K/day) for solar zenith angle SZ1 (light grey), SZ2 (grey), and SZ3 (black). Mid-latitude summer (top), mid-latitude winter (middle) and tropical (bottom) climatological profiles. 

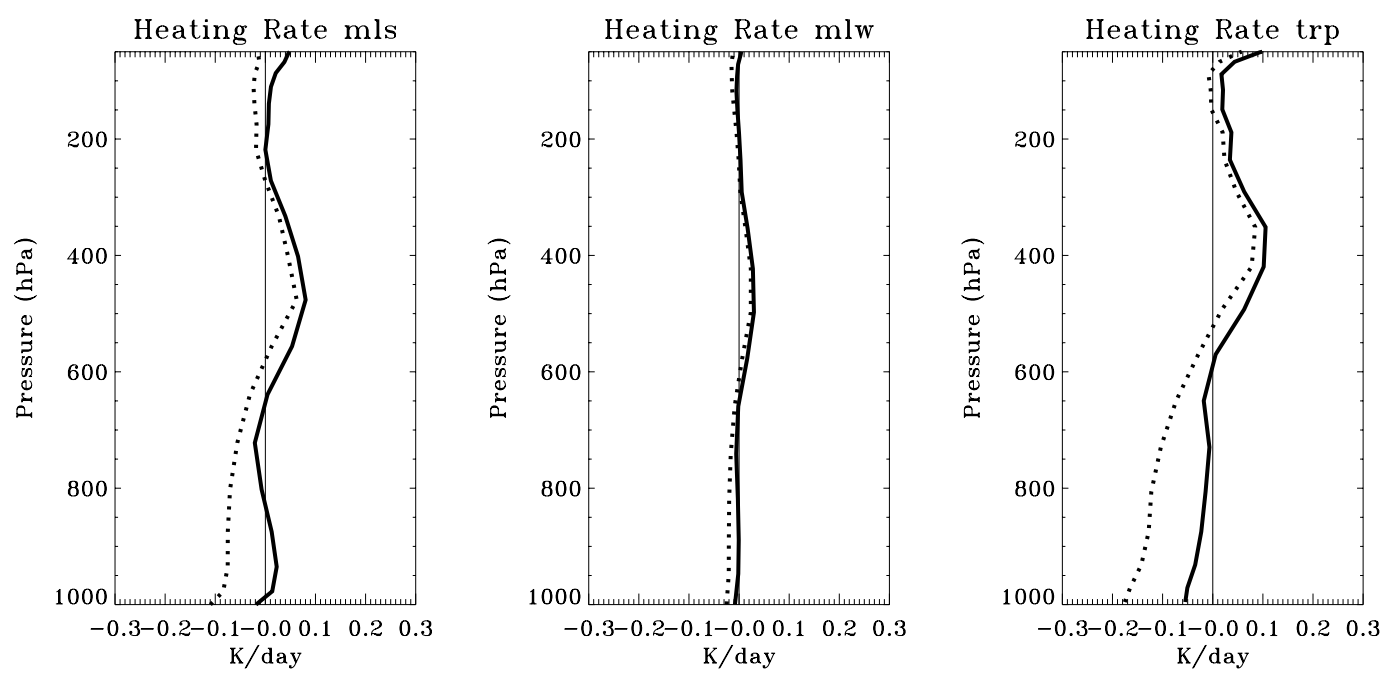

Fig. 2. Difference of daily averaged clear-sky shortwave heating rates (K/day) for SW6-LBL (continuous curve) and SW4-LBL (dotted curve) for the troposphere. Mid-latitude summer (let), mid-latitude winter (middle) and tropical (right) climatological profiles.

with respect to LBL up to $2 \mathrm{~K} /$ day. The largest bias in the SW4 heating rate is found for the mid-latitude summer case. The SW6-LBL difference in the daily averaged shortwave heating rate is instead close to zero for all the cases considered, indicative of a substantial improvement. The increased absorption in SW6 with respect to SW4 is mainly due to the separation of the $250-690 \mathrm{~nm}$ band, that allows for a better distinction of the Hartley and Chappuis bands, and to the inclusion of the shortwave end of the Hartley bands in the 185$250 \mathrm{~nm}$ band. The separation of the weak and strong ozone absorption regimes therefore leads to a better parameterization.

However, in the mesosphere, the SW6 performance does not agree so well with the LBL and a clear improvement cannot be concluded (the maximum bias is $1.5 \mathrm{~K} /$ day at $0.1 \mathrm{hPa}$ ). This result is consistent with the fact that oxygen absorption is not included in the first band of the SW6, whilst it is considered in the LBL calculations (part of the negative bias is due to neglecting the oxygen absorption). In addition, the heating rate maximum moves upward with increasing zenith angles at a faster rate than the LBL (Fig. 1, right).

In the lower troposphere (Fig. 2), the SW6 daily averaged heating rates are again in better agreement with he LBL model, while in the middle and upper troposphere the SW4 and SW6 differences to the LBL are comparable for the three cases considered.

The comparisons reported in Fig. 1 and 2 are consistent with that of Iacono et al. (2002).

\section{Radiative and dynamical response in the Middle Atmosphere GCM}

\subsection{Changes in the middle atmosphere}

Figure 3 shows the January zonal mean shortwave heating rate (20-year average) for the EXP simulation and for the EXP-CTRL difference. In the summer hemisphere, the January zonal-mean heating rate is largest (12-16 K/day) at $1 \mathrm{hPa}$. The EXP-CTRL difference is always positive and ranges between 0.2 and $1.8 \mathrm{~K} /$ day above $10 \mathrm{hPa}$. The largest difference occurs at $1 \mathrm{hPa}$ south of $60^{\circ} \mathrm{S}$. In the summer middle atmosphere the zonal mean January heating rates of EXP are about $12 \%$ larger than the CTRL heating rates.

The January zonal mean temperature for EXP, CTRL and the NCEPCPC (National Centers for Environmental Prediction and Climate Prediction Center) analysis (1980-1999) are shown in Fig. 4. The temperature difference between EXP and CTRL (Fig. 4, top-right) is positive almost everywhere. Between $60^{\circ} \mathrm{N}$ and $90^{\circ} \mathrm{S}$, the difference ranges from 1 to $3 \mathrm{~K}$ in the lower stratosphere and from 3 to $7 \mathrm{~K}$ in the upper stratosphere and mesosphere. Above $100 \mathrm{hPa}$, the difference is always significant south of $60^{\circ} \mathrm{N}$. The warmer EXP temperatures are in better agreement with NCEPCPC, especially at the summer hemisphere stratopause. The zonal mean temperature for the CTRL simulation is generally colder than the NCEPCPC analysis. At $1 \mathrm{hPa}$, south of $60^{\circ} \mathrm{S}$, the NCEPCPC January temperatures are up to $290 \mathrm{~K}$, whereas the CTRL temperatures do not reach $280 \mathrm{~K}$.

The seasonal cycle of monthly zonal mean temperature differences (CTRL-NCEPCPC) and the (EXP-CTRL) at the stratopause $(1 \mathrm{hPa})$ are shown in Fig. 5. With the exception of the southern polar region in winter, the CTRL temperature 
bias is generally negative. In the tropics and summer hemispheres, the CTRL-NCEPCPC temperature difference ranges typically from 8 to $14 \mathrm{~K}$. This cold bias is substantially reduced in the EXP simulation, as shown by the positive and significant EXP-CTRL temperature difference (Fig. 5, right). Except for polar winter conditions the EXP temperature is 6 to $8 \mathrm{~K}$ warmer than the CTRL temperature, throughout the year. The climatological temperature bias at the stratopause is therefore reduced of about a factor 2 for the EXP simulation, in better agreement with the NCEPCPC analysis.

In summary, Figs. 4 and 5 demonstrate that the direct consequence of the increase in the shortwave heating rate (mainly due to increased ozone absorption) is a significant warming of most of the modeled atmosphere. Instead, the warming that occurs in polar night conditions in the winter polar mesosphere (Fig. 4, top right) in EXP with respect to CTRL cannot be directly associated with the change in the shortwave heating rates. As it is shown later, this warming is understood to be a dynamical response to the changes in the radiation parameterization.

The 20 years average of the January zonal mean zonal winds for EXP and for the (EXP-CTRL) difference are shown in Fig. 6 (top). The largest differences in zonal mean zonal wind occur at the stratopause and in the mesosphere, where the temperature differences are larger (Figs. 4 and 5). The significant differences in zonal wind that occur close to the stratopause indicate stronger jets in each hemisphere: Increased easterlies in the Southern Hemisphere (up to $10 \mathrm{~m} / \mathrm{s}$ ) and increased westerlies (up to $8 \mathrm{~m} / \mathrm{s}$ ) in the Northern Hemisphere.

The enhanced easterlies and westerlies for the EXP simulation with respect to the CTRL simulation are a direct radiative response: they are due to the increased North Pole to South Pole temperature gradient (Fig. 4), resulting from the summer hemisphere and tropical radiative warming. Therefore, the direct impact of the change in the radiation parameterization is an enhancement of the climatological solstitial condition in the middle atmosphere.

In order to estimate indirect dynamical changes associated with the implementation of the SW6 parameterization, the net heating rate for EXP and for the EXP-CTRL difference is shown in Fig. 6 (bottom panels). The EXP net heating rate is positive in the summer hemisphere and negative in the winter hemisphere, implying upward circulation in summer and downward in winter (Andrews et al., 1987). In the mesosphere, the EXP-CTRL net heating rate difference is positive in the summer and negative in the winter hemisphere. Therefore, the climatological circulation in the mesosphere is increased in the EXP simulation with respect to the CTRL. The circulation change deduced by the change in the net heating rate indicates that in the mesosphere there is a dynamical response to the implementation of the SW6 parameterization, namely adiabatic cooling by upward motion in summer and warming by downward motion in winter.
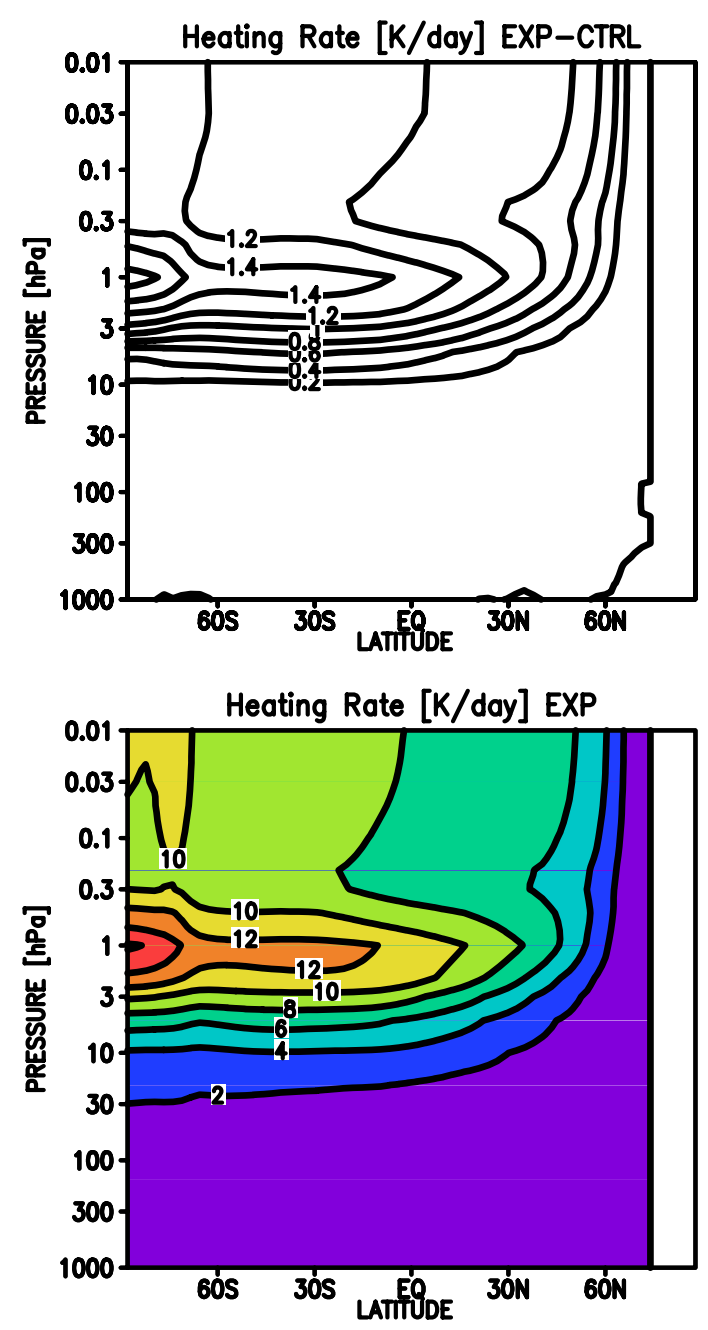

Fig. 3. Top: January zonal mean shortwave heating rate (K/day): (top) for the EXP-CTRL difference, contour interval is $0.2 \mathrm{~K} /$ day; (bottom) for the EXP simulation, contour interval is $2 \mathrm{~K} /$ day.

These considerations are indeed consistent with the EXPCTRL temperature difference shown in Fig. 4 (upper right). In the summer hemisphere, the dynamical cooling competes with the strong radiative local warming, reducing it (indeed, the maximum warming of $7 \mathrm{~K}$ reduces above $0.1 \mathrm{hPa}$, even if the heating rates difference ranges between 1.2 and $1.4 \mathrm{~K} /$ day in the mesosphere). In the winter hemisphere, the increased downward motion and the consequent dynamical warming is observed above $0.3 \mathrm{hPa}$, while below the direct radiative response is seen.

Note that Fig. 6 shows also additional substructures in the EXP-CTRL net heating rates difference, mainly as a positive (negative) difference at $30^{\circ} \mathrm{N}$ above/below $1 \mathrm{hPa}$ and a positive net heating rate difference north of $60^{\circ} \mathrm{N}$, below $1 \mathrm{hPa}$. These substructures are again consistent with the temperature difference structures shown in Fig. 4. 

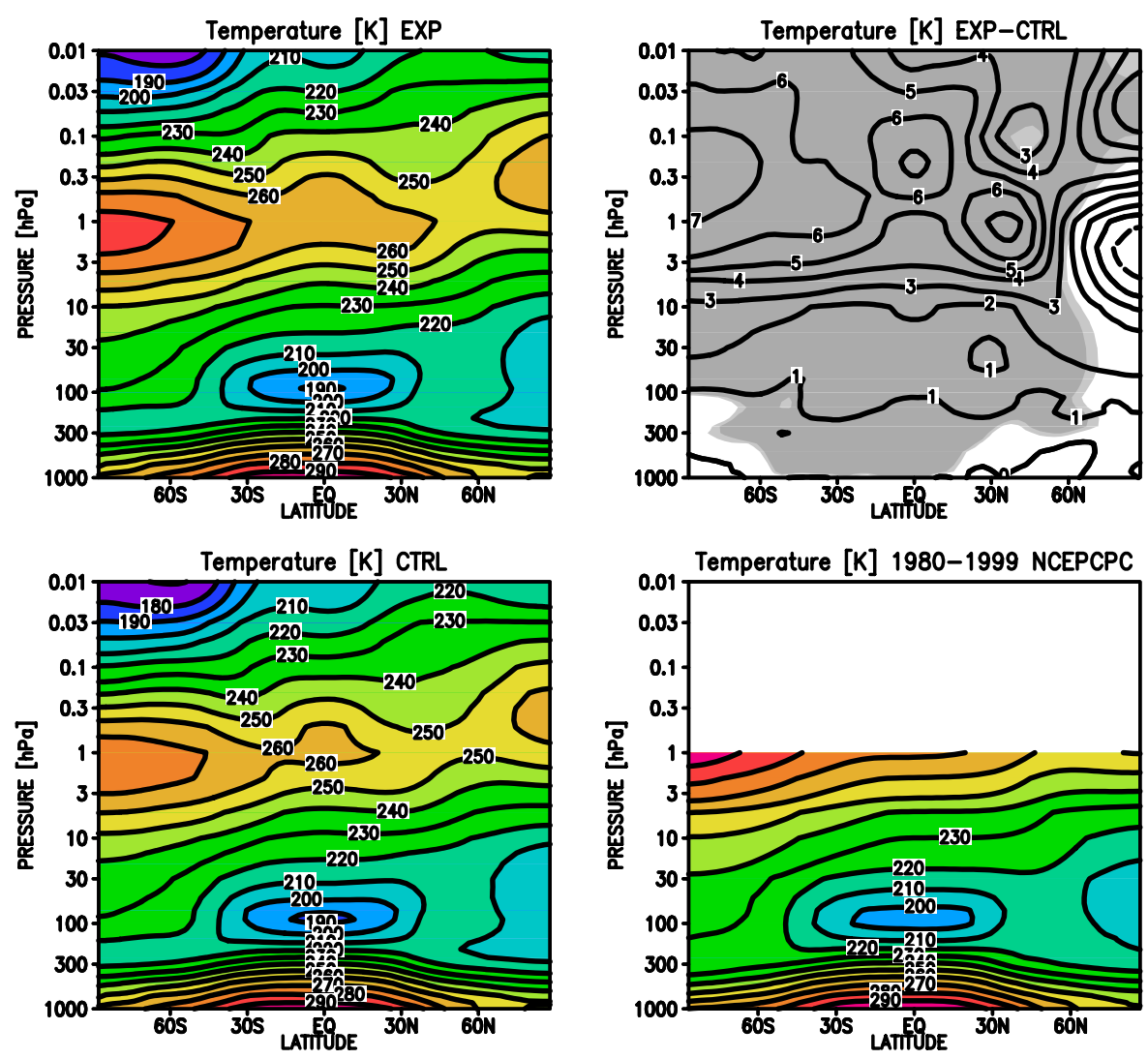

Fig. 4. January zonal mean temperature (K): (top left) for the EXP simulation; (top right) for the EXP-CTRL difference; (bottom left) for the CTRL simulation; and (bottom right) for the NCEPCPC analysis. Contour intervals is $1 \mathrm{~K}$ for the top right panel, and $10 \mathrm{~K}$ for the other three panels. For the top right panel, light and dark grey shades indicate statistical significance at the $95 \%$ and $99 \%$ levels, respectively.

A plausible explanation for the induced dynamical changes in the mesosphere is a change in the gravity wave filtering in the stratosphere induced by the reported enhancement at the wind jets (Fig. 6 upper right): In the summer (winter) stratosphere, stronger easterlies (westerlies) at $1 \mathrm{hPa}$ imply an increase of the wind shear at and below the easterly (westerly) jet core. At the stratopause, the net momentum flux carried by the gravity waves is thereafter more positive (negative) in the summer (winter) hemisphere. Above, in the mesosphere, this situation facilitates the deceleration of the easterlies (westerlies) in the summer (winter) hemisphere leading to an increased circulation (upward in summer and downward in winter). It is not the purpose of the current work to detail this chain of effects, because this behavior of the gravity wave parameterization in the MAECHAM models has been documented and discussed in earlier works (Manzini and McFarlane, 1998; Manzini et al., 2003), although the changes in the background winds occurred for different reasons.

The January results are supported by the July temperatures, zonal mean zonal winds and net heating rates (Fig. 7). The July EXP-CTRL temperature difference (Fig. 7 top- right) is very similar to the January difference (Fig. 4), but in the polar stratopause in the summer hemisphere the difference is larger in January (7 K, Fig. 4) than in July (6 K, Fig. 7). July zonal mean zonal wind differences (Fig. 7 middle-right) are significant near the stratopause, as for January, with increased easterlies in the Northern Hemisphere (up to $8 \mathrm{~m} / \mathrm{s}$ ) and increased westerlies south of $50^{\circ} \mathrm{S}$ (up to $6 \mathrm{~m} / \mathrm{s}$ ). January shortwave heating rates are larger than July heating rates (not shown); a possible reason is that in January the Earth is near the perihelion. Moreover, close to the South Pole (winter hemisphere), a highly significant $6 \mathrm{~K}$ difference occurs above the stratopause. As for January, this warming is consistently associated with an increased downward circulation, deduced by the negative net heating rates difference (Fig. 7, bottom-right).

\subsection{Changes in the troposphere}

In the troposphere, changes in the averaged temperature can be due to both the increased spectral resolution and the implementation of a different treatment of the cloud optical properties. Given that the focus of this work is on the 

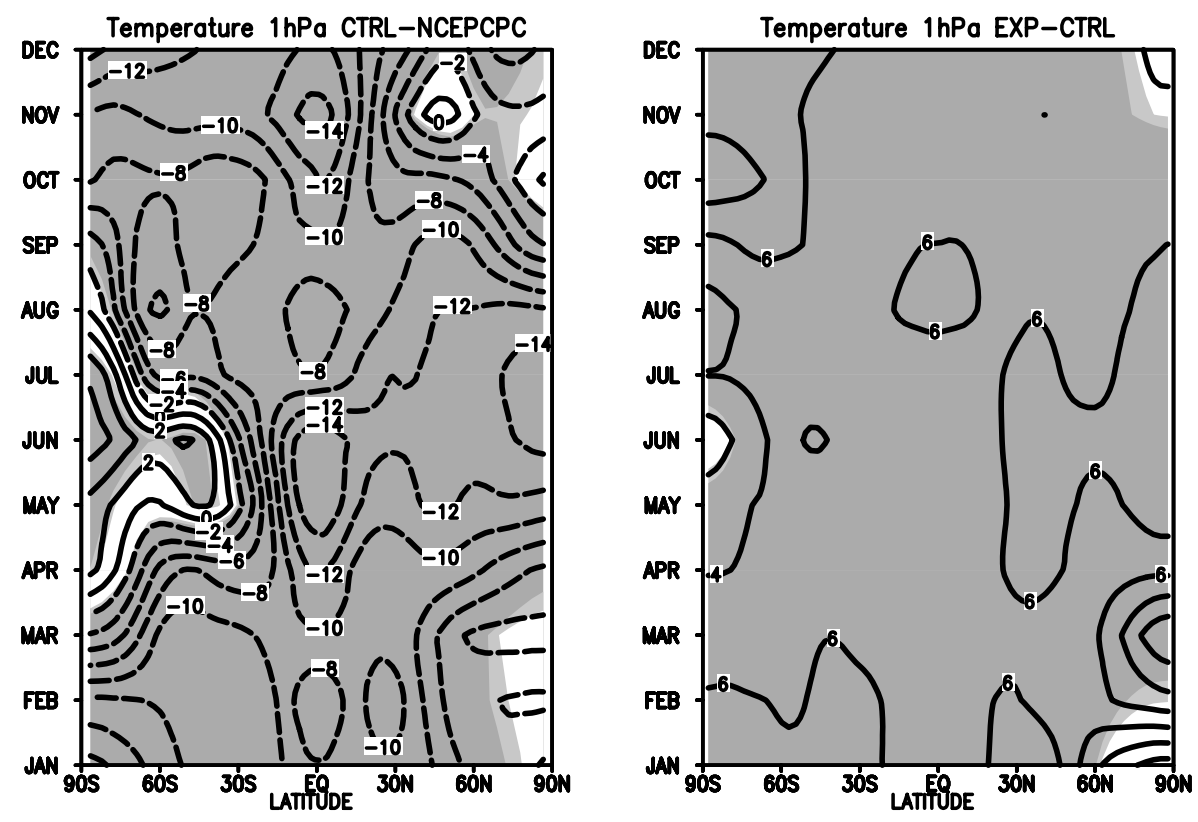

Fig. 5. Latitude-time section of monthly zonal mean temperature (K) difference at $1 \mathrm{hPa}$ : (left) CTRL simulation - NCEPCPC analysis; (right) EXP simulation - CTRL simulation. Contour interval is $2 \mathrm{~K}$. Light and dark grey shades indicate statistical significance at the $95 \%$ and $99 \%$ levels, respectively.

stratosphere, the impact of the SW6 parameterization on the troposphere is here only briefly reported.

Roeckner et al. (2006) have documented a general cold bias of the ECHAM5 model in the troposphere which depends on the resolution. For a comparable resolution as used here, they find for December-January-February zonal mean temperature differences between ECHAM5 and ERA40 of -0.5 to $-2 \mathrm{~K}$ below $200 \mathrm{hPa}$ and $-2 \mathrm{~K}$ to $-4 \mathrm{~K}$ above $200 \mathrm{hPa}$ in the $30^{\circ} \mathrm{S}-30^{\circ} \mathrm{N}$ region (Fig. 3 top-left of Roeckner et al., 2006).

Figure 8 shows the 20-years average annual and zonal mean EXP shortwave heating rates, temperature and water vapor fields for the troposphere, together with the annual and zonal mean EXP-CTRL differences.

The EXP-CTRL heating rate difference is always positive. Consequently, also the temperature difference is always positive and it is larger above $400 \mathrm{hPa}$ (greater than $0.5 \mathrm{~K}$ ). Smaller differences are found for the lower troposphere and close to the surface $(0.5-1 \mathrm{~K}$ between 400 and $200 \mathrm{hPa}$; 0 $0.5 \mathrm{~K}$ between the surface and $400 \mathrm{hPa}$ ). The general increase in the heating rate and temperature is consistent with the clear sky SW6-LBL comparison for the troposphere. Therefore, this warming of the troposphere can be attributed to the changes in the radiative properties of both the troposphere and the stratosphere. In the simulations, the reported changes in the clouds optical properties may have also contributed to the warming of the troposphere, although only small differences have been found in the ice and liquid water cloud distributions between the CTRL and EXP cases (not shown).
The EXP-CTRL water vapour difference, in percentage, is always positive, consistent with a warmer troposphere and possibly reinforcing the warming. In the Southern Hemisphere and in the Northern Hemisphere south of $30^{\circ} \mathrm{N}$, below $500 \mathrm{hPa}$, EXP is about $3 \%$ moister than CTRL, and between $200-500 \mathrm{hPa}$ it is $3-9 \%$ moister. North of $30^{\circ} \mathrm{N}$, the lower and middle troposphere is 6\%-9\% moister in the EXP case than in the CTRL, in agreement with the temperature difference (more pronounced in the Northern than in the Southern Hemisphere). Above $200 \mathrm{hPa}$, in a relatively dry region, EXP is $12 \%$ to $30 \%$ moister than CTRL, with the largest differences observed at the Equator.

\section{Conclusions}

The shortwave radiation parameterization of the MAECHAM5 model has been upgraded following the ECMWF approach, by increasing its spectral resolution from 4 to 6 bands and changing the optical properties of the clouds accordingly. To test the 4 and 6-band radiation parameterizations, offline comparisons with a LBL model have been carried out for a number of cases and solar zenith angles. The reported results show a general improvement of the 6-band scheme with respect to the 4-band scheme, in terms of shortwave surface fluxes and heating rates. In the upper stratosphere, the region specifically targeted in this work, the SW4 parameterization bias of 1 to $2 \mathrm{~K} /$ day (daily average) with respect to the LBL has been virtually eliminated. Therefore, the 6 band shortwave radiation 

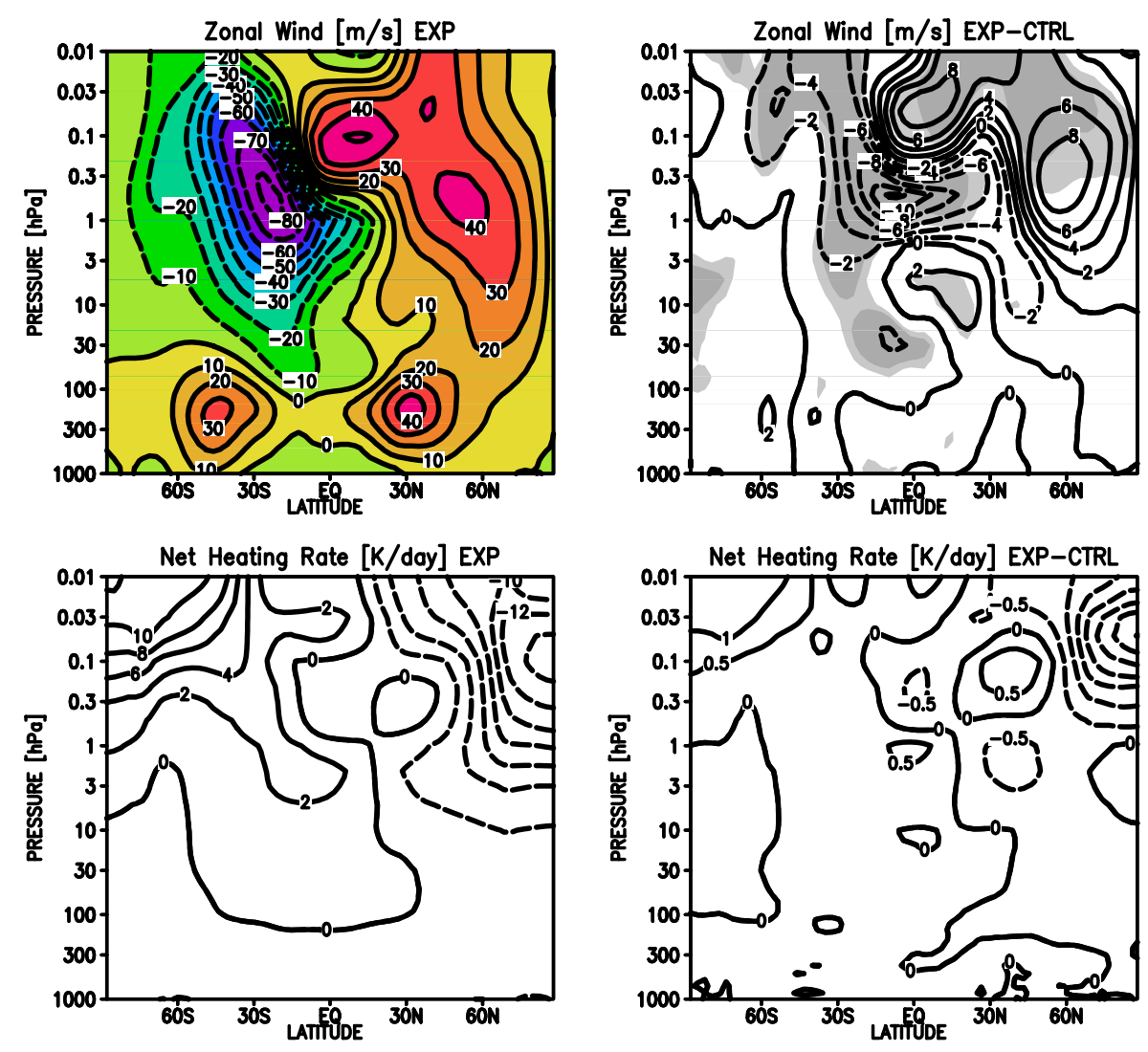

Fig. 6. Top: January zonal mean zonal wind (m/s): (left) for the EXP simulation, contour interval is $10 \mathrm{~m} / \mathrm{s}$, and (right) for the EXP - CTRL difference, contour interval is $2 \mathrm{~m} / \mathrm{s}$. Bottom: January zonal mean net heating rate (K/day): (left) for EXP simulation, contour interval is $2 \mathrm{~K} /$ day, and (right) for the EXP - CTRL difference contour interval is $0.5 \mathrm{~K} /$ day. For the top right panel: light and dark grey shades indicate statistical significance at the $95 \%$ and $99 \%$ levels, respectively.

parameterization is considered to be better suited for the representation of the ozone absorption in the stratosphere than the 4 band parameterization. Figures 3 to 8 provide evidence that the 6 band Fouquart and Bonnel scheme produces heating rates that are accurate enough for the simulation of the troposphere and stratosphere system in the MAECHAM5 model.

Two 20-years simulations with the MAECHAM5 GCM have been performed, the first (CTRL) with the 4-band scheme and the second (EXP) with the 6-band scheme. In the middle atmosphere, it is found that the shortwave heating rate in the summer hemisphere is larger in EXP than in CTRL (up to $1.8 \mathrm{~K} /$ day), following the expectation from the comparison with the LBL.

The direct consequence of the change in the shortwave heating rate is a significant warming of almost the entire middle atmosphere, largest at the summer stratopause and in the mesosphere ( $5 \mathrm{~K}$ to $7 \mathrm{~K}$ ), leading to an enhancement of the climatological solstitial condition in the middle atmosphere.

At the stratopause, the improved representation of the ozone absorption has therefore substantially alleviated the mean temperature bias in the summer hemisphere.
The EXP-CTRL warming of the middle atmosphere has the following dynamical consequences:

1. Direct radiative response: The enhanced winter to summer pole temperature gradient at the stratopause produces stronger easterlies (westerlies) in the summer (winter) hemisphere, in the middle atmosphere. The changes in the winds are largest at the stratopause.

2. Indirect dynamical response caused by the enhanced wind jets: Dynamical cooling occurs in the polar summer mesosphere and dynamical warming in the polar winter mesosphere. While the former is masked by direct radiative warming, the latter dominates the temperature response in both January and July. The indirect dynamical response can be understood as a change in the gravity wave filtering in the stratosphere induced by the direct radiative response in the zonal mean winds and is consistent with the reported changes in the net heating rates.

In the troposphere, an annual mean warming of $0.5 \mathrm{~K}$ is found in the middle troposphere and a warming of 1 to $1.5 \mathrm{~K}$ 

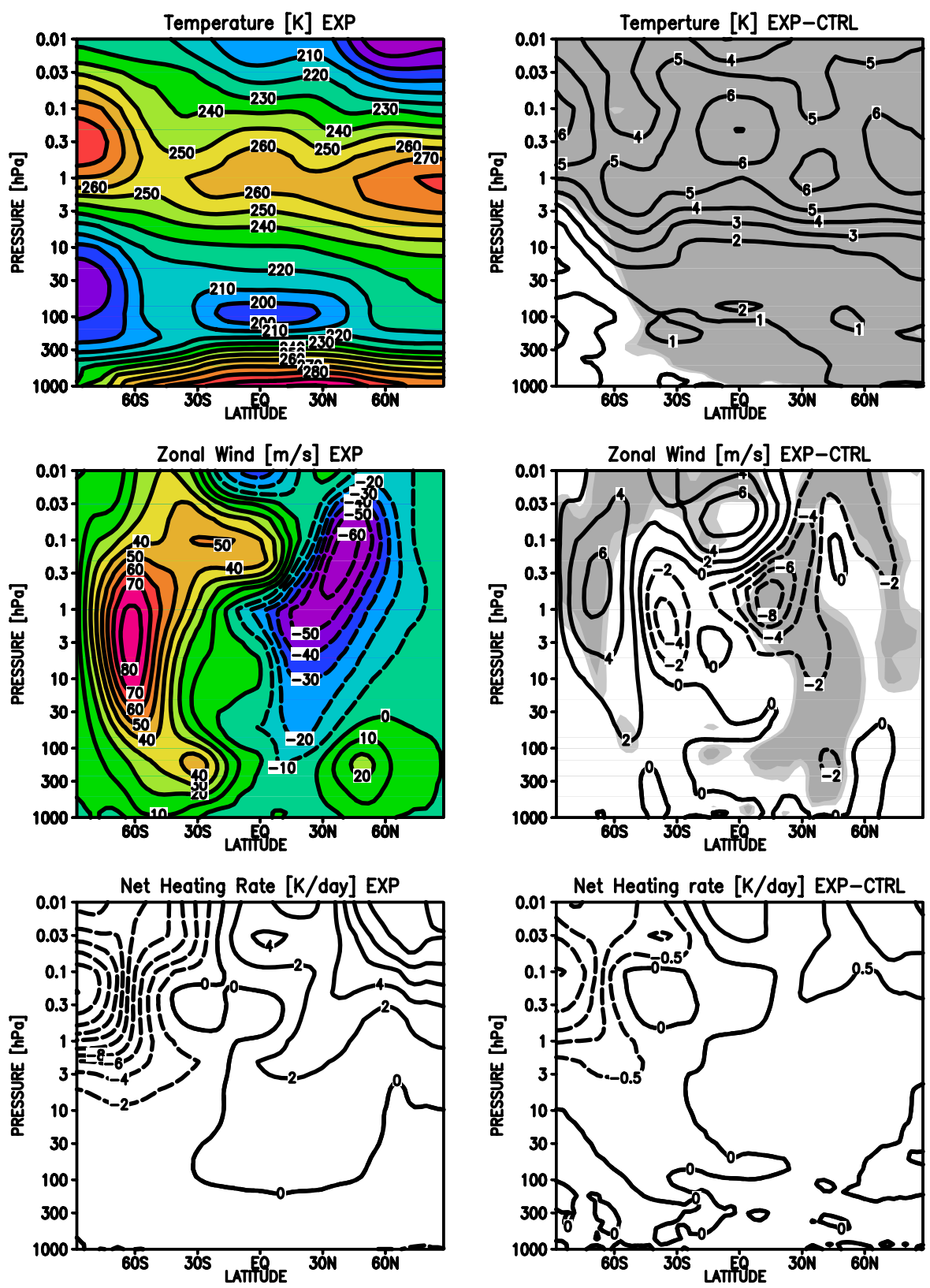

Fig. 7. Top: July zonal mean temperature (K): (left) for the EXP simulation, contour interval is $10 \mathrm{~K}$, and (right) for the EXP - CTRL difference, contour interval is $1 \mathrm{~K}$. Middle: July zonal mean zonal wind $(\mathrm{m} / \mathrm{s})$ : (left) for the EXP simulation, contour interval is $10 \mathrm{~m} / \mathrm{s}$, and (right) for the EXP - CTRL difference, contour interval is $2 \mathrm{~m} / \mathrm{s}$. Bottom: July zonal mean net heating rate (K/day): (left) for EXP simulation, contour interval is $2 \mathrm{~K} /$ day, and (right) for the EXP - CTRL difference contour interval is $0.5 \mathrm{~K} /$ day. For the right top and middle panels: light and dark grey shades indicate statistical significance at the $95 \%$ and $99 \%$ levels, respectively.

in the upper troposphere. Consistently with the warming, on annual average the troposphere shows a moistening (3\% to $9 \%$ in the middle troposphere, $12 \%$ to $30 \%$ above $200 \mathrm{hPa}$ ). With respect to Roeckner et al. (2006), the temperature difference in the troposphere therefore indicates an improvement of the modelled climatology when the SW6 parameterization is used.
It is important to note that the current results, although significant, are limited by the specification of the ozone distribution in the model. Namely, an atmosphere model with fixed ozone neglects the feedback between temperature and ozone, particularly large in the upper stratosphere. Ultimately, a consistent comparison with satellite data of modelled stratospheric temperatures will have to be done with results from 

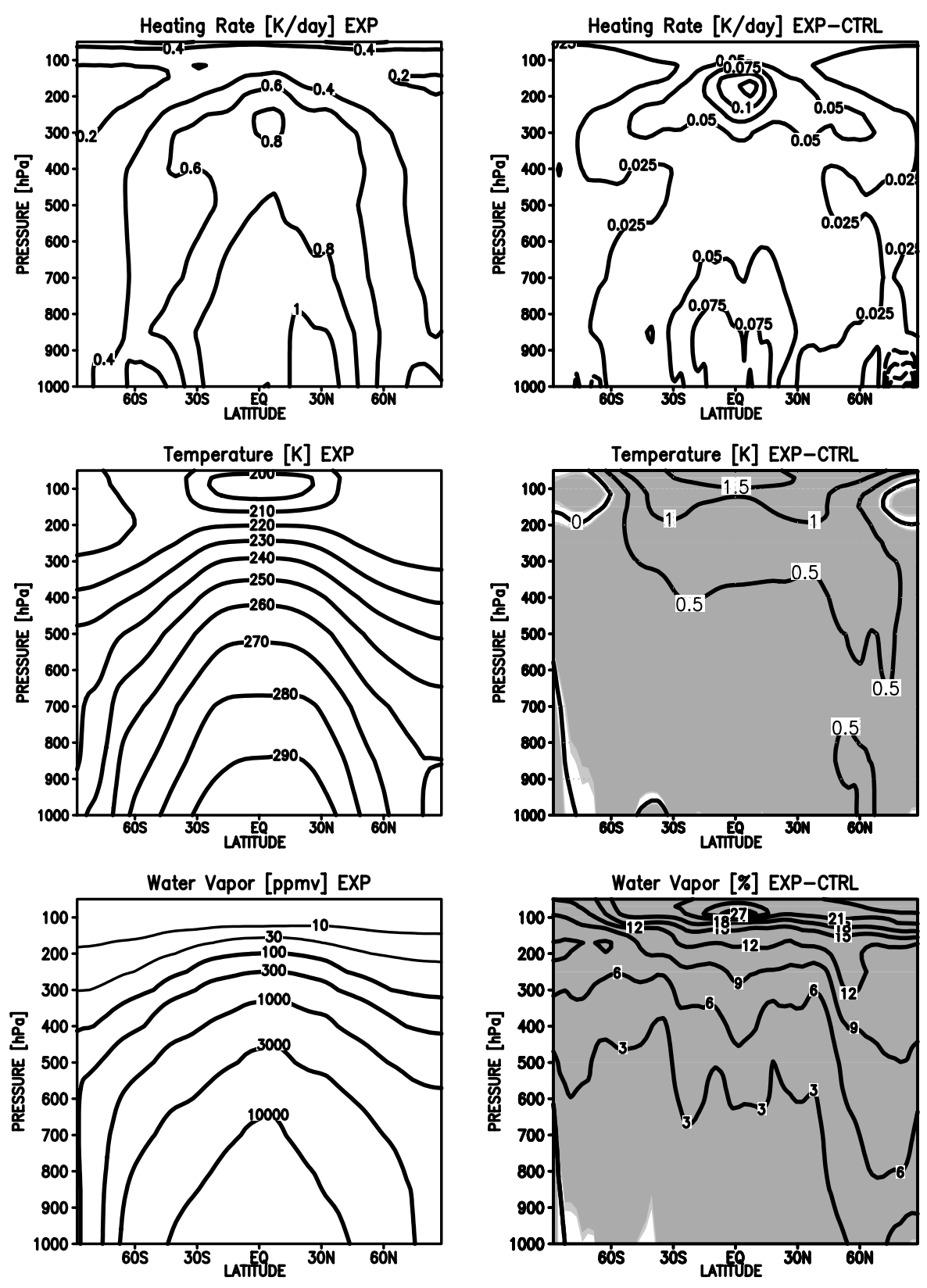

Fig. 8. Top: Annual zonal mean shortwave heating rate (K/day): (left) for the EXP simulation, contour interval is $0.2 \mathrm{~K} /$ day, and (right) for the EXP - CTRL difference, contour interval is $0.025 \mathrm{~K} /$ day. Middle: Annual zonal mean temperature (K): (left) for the EXP simulation, contour interval is $10 \mathrm{~K}$, and (right) for the EXP - CTRL difference, contour interval is $0.5 \mathrm{~K}$. Bottom: Annual zonal mean water vapor: (left) for the EXP simulation in ppmv, contour interval: 10000, 3000, 1000, 300, 100, 30, 10, 3, 1 ppmv, and (right) for the EXP - CTRL difference in $\%$, contour interval is $3 \%$.

Chemistry Climate Models. Therefore, it will be of interest to evaluate the impact of the SW6 parameterization on the stratospheric temperatures of a version of the MAECHAM5 model that is coupled to a chemistry model.

The current study has shown that the increased spectral resolution in the UV-Visible part of the spectrum and possibly also the associated changes in the cloud optical properties have had significant impacts on the troposphere, for both the global climatological temperature and water vapor distributions. Close to the Earth's surface, these changes have been mitigated by the imposed sea surface temperatures. In the case of a coupled atmosphere ocean GCM, such changes in the transfer of the atmosphere would have instead led to a different surface climate equilibrium. Therefore, our results 
point to the importance of including a proper representation of the shortwave radiation parameterization also in coupled atmosphere ocean GCMs.

Acknowledgements. Part of this work was supported by the EC SCOUT Integrated Project (505390-GOCE-CT-2004). We are grateful to Antonio Navarra and Erich Roeckner for constructive comments and valuable discussions on the manuscript.

Edited by: Y. Balkanski

\section{References}

Andrews, D. G., Holton, J. R., and Leovy, C. B., Middle Atmospheric Dynamics, Academic, San Diego, CA, 489 pp., 1987.

Collins, W. D., Ramaswamy, V., Schwarzkopf, M. D., et al.: Radiative forcing by well-mixed greenhouse gases: Estimates from climate models in the Intergovernmental Panel on Climate Change (IPCC) Fourth Assessment Report (AR4), J. Geophys. Res., 111, D14317, doi:10.1029/2005JD006713, 2006.

Dubuisson, P., Buriez, J. C., and Fouquart, Y.: High Spectral Resolution Solar Radia- tive Transfer in Absorbing and Scattering Media: Application to the Satellite Simulation, J. Quant. Spectrosc. Radiat. Transfer, 55, 103-126, 1996.

Dudhia, A.: RFM v3 software user's manual, Tech. Rep. ESA POMA-OXF-GS-0003, Atmos., Oceanic and Planet. Phys., Clarendon Lab., Oxford, U.K., 1997.

Ebert, E. E. and Curry, J. A.: A parameterization of cirrus cloud optical properties for climate models, J. Geophys. Res., 97, 38313836, 1992.

Egorova, T., Rozanov, E., Zubov, V., Manzini, E., Schmutz, W., and Peter, T.: Chemistry-climate model SOCOL: a validation of the present-day climatology, Atmos. Chem. Phys., 5, 1557-1576, 2005 , http://www.atmos-chem-phys.net/5/1557/2005/.

Eyring, V., Harris, N. R. P., Rex, M., et al.: A Strategy for ProcessOriented Validation of Coupled Chemistry Climate Models, Bull. Am. Meteorol. Soc., 86, 1117-1133, doi:10.1175/BAMS-86-8$1117,2005$.

Fouquart, Y. and Bonnel, B.: Computations of solar heating of the Earth s atmosphere: A new parameterization, Beitr. Phys. Atmos., 53, 35-62, 1980.

Fouquart, Y., Bonnel, B., Brogniez, G., Buriez, J. C., Smith, L., Morcrette, J. J., and Cerf, A.: Observations of Saharan aerosols: results of ECLATS field experiment. Part II: broadband radiative characteristics of the aerosols and vertical radiative flux divergence, J. Clim. Appl. Meteor., 26, 38-52, 1987.

Halthore, R. N., Crisp, D., Schwartz, S. E., et al: Intercomparison of shortwave radiative transfer codes and measurements, J. Geophys. Res., 110, D11206, doi:10.1029/2004JD005293, 2005.

Hines C. O.: Doppler spread parametrization of gravity wave momentum deposition in the middle atmosphere, 1, Basic formulation, J. Atmos. Solar Terr. Phys., 59, 371-386, 1997.
Iacono, M. J., Delamere, J. S., Mlawer, E. J., and Clough, S. A.: Cloudy Sky RRTM Shortwave Radiative Transfer and Comparison to the Revised ECMWF Shortwave Model, Twelfth ARM Science Team Meeting Proceedings, St. Petersburg, Florida, 812 April, Atmospheric and Environmental Research, Inc. Lexington, Massachusetts, 2002.

Lott, F. and Miller, M.: A new subgrid scale orographic drag parameterization; its testing in the ECMWF model, Q. J. Roy. Meteorol. Soc., 123, 101-127, 1997.

Manzini, E., Giorgetta, M. A., Esch, M., Kornblueh, L., and Roeckner, E.: The influence of sea surface temperatures on the Northern winter stratosphere: Ensemble simulations with the MAECHAM5 model, J. Climate, 19, 3863-3881, 2006.

Manzini, E. and McFarlane, N. A.: The effect of varying the source spectrum of a gravity wave parameterization in a middle atmosphere general circulation model, J. Geophys. Res., 103, 31523 $31539,1998$.

Manzini, E., Steil, B., Bruehl, C., Giorgetta, M. A., and Krueger, K.: A new interactive chemistry-climate model: 2. Sensitivity of the middle atmosphere to ozone depletion and increase in greenhouse gases and implications for recent stratospheric cooling, J. Geophys. Res., 108(D14), 4429, doi:10.1029/2002JD002977, 2003.

Morcrette, J. J., Mlawer, E. J., Iacono, M. J., and Clough, S. A.: Impact of the radiation-transfer scheme RRTM in the ECMWF forecast system, Technical Report in the ECMWF Newsletter, No. 91, 2001.

Pawson, S., Kodera, K., Hamilton, K., et al.: GCM-Reality Intercomparison Project for SPARC: Scientific Issues and Initial Results, Bull. Am. Meteorol. Soc., 81, 781-796, 2000.

Roeckner, E., Brokopf, R., Esch, M., et al.: Sensitivity of Simulated Climate to Horizontal and Vertical Resolution in the ECHAM5 Atmosphere Model, J. Climate, 19, 3771-3791, doi:10.1175/JCLI3831.1, 2006.

Roeckner, E., Bäuml, G., Bonaventura, L., et al.: The atmospheric general circulation model ECHAM5. Part I: Model description, Max Planck Institute for Meteorology Rep. 349, 127 pp., 2003.

Stamnes, K., Tsay, S. C., Wiscombe, W., and Jayaweera, K.: A numerically stable algorithm for discrete-ordinate-method radiative transfer in multiple scattering and emitting layered media, Appl. Opt., 27, 2502-2509, 1998.

Steil, B., Bruehl, C., Manzini, E., Crutzen, P. J., Lelieveld, J., Rasch, P. J., Roeckner, E., and Krueger, K.: A new interactive chemistry-climate model: 1 . Present-day climatology and interannual variability of the middle atmosphere using the model and 9 years of HALOE/UARS data, J. Geophys. Res., 108(D9), 4290, doi:10.1029/2002JD002971, 2003.

Wild, M. and Roeckner, E.: Radiative fluxes in the ECHAM5 general circulation model, J. Climate, 19, 3792-3809, 2006. 